\title{
CONCEPTS
}

\section{Antisnake Venom Production Crisis-Who Told Us It Was Uneconomic and Unsustainable?}

\author{
Ian D. Simpson, BSc, PG (Dip); Ingrid M Jacobsen, BA (Ind. Econ) \\ From the Snakebite Advisor, Pakistan Medical Research Council Islamabad, Pakistan and Tamil Nadu Snakebite Taskforce, Chennai, India \\ (Dr Simpson)
}

\begin{abstract}
The world of antisnake venom production is currently a gloomy place to visit. It is described as being in crisis, characterized by shortages, producers leaving the market, high prices, and unsustainability. It has been reduced to a pauper-like status, doomed to relying on charitable handouts for resolution. The worrying aspect of this is that little work has been done to establish the true economics and return on antisnake venom if provided by private companies. Fortunately, it is amenable to economic analysis, and in this manner, a rational approach to further development and distribution can be obtained. This article proposes a model antisnake venom (ASV) production unit and shows the likely economics and return based on the production of various volumes of ASV. It estimates the costs for the key components of the unit, which are production equipment and staffing. A profit and loss account and balance sheet are constructed for the unit, and the effects of ASV volume and neutralizing titres are demonstrated. It is our contention that ASV production can be sustained at affordable prices in the developing world. We recommend that any solution to the ASV shortage must take into account the most cost efficient method(s) of production.
\end{abstract}

Key words: snakebite, antisnake venom, antivenom production, envenoming, World Health Organization, antivenom economics

\section{Introduction}

A manufacturer considering the production of an antisnake venom (ASV) can be forgiven for focusing upon other products instead. The World Health Organization (WHO) states that private producers have stopped producing ASV because of "market instability and unprofitability; the prices of some products are completely unaffordable by the health systems of developing countries." ${ }^{1}$ Despite this gloomy assessment, the constant plea by clinicians on behalf of snakebite victims for more ASV has been made for decades. ${ }^{2-16}$

To date, there is not agreement upon the best way to meet this pressing need. No detailed instructions or analysis for the economical production of ASV has been provided to convince private manufacturers to enter the commercial market or to establish why government suppliers are leaving the market; indeed, there is scant publication about ASV in any market. ${ }^{17}$ This article presents a model for ASV production, primarily in a developing

Corresponding author: Ian D. Simpson, Kooran House Nayathode, Kerala 683572 India (e-mail: iandsimpson@gmail.com). country and based on corresponding cost considerations. However, the key variables identified here for the first time can be used for comparison with costs for these same variables in any country (Table 1).

\section{Background assumptions}

A critical problem, and one of the major causes for the past 30 years of failure to solve the snakebite problem, is ASV provision and economic sustainability. In the absence of charitable distribution, of which there is no track record of success, the product must be affordable in developing countries while delivering an economic return that incentivizes producers to continue production. Based upon this premise, our model assumes that ASV production is the core business and that those discrete areas essential to the "ASV process," but not necessarily production per se, will be outsourced to more efficient suppliers. For example, consider the need for a snake house, where snakes are "milked" of venom for collection in requisite quantities for efficient ASV production. Managing a snake house and snake handling are 
Table 1. Key variables in the developing world model for comparison with other locations

\begin{tabular}{ll}
\hline \multicolumn{1}{c}{ Key measure } & Value \\
\hline Grazing land cost per acre & $\$ 30664$ \\
Land allocation per horse & 0.5 acres \\
General construction costs per square foot & $\$ 25$ \\
Venom costs per vial produced & $\$ 0.38$ \\
$\begin{array}{ll}\text { Average annual labor cost for key scientific em- } \\
\text { ployees per employee }\end{array}$ & $\$ 12000$ \\
\hline
\end{tabular}

specialist occupations, particularly if producing an ASV for nonindigenous species. In such a case, it may be far simpler to purchase venom from reputable suppliers, and we have made sensible assumptions such as this throughout our model. In another example, ancillary products, such as sterile water-for-injection, used in reconstituting lyophilized ASV, may be economically purchased from suppliers that can generate better economies of scale and thereby reduce the overall cost of the ASV. We address all areas of production, always on the lookout for expertise, low cost, and economies of scale.

\section{The ASV product}

Despite all the debate and demands for more ASV, the characteristics of the product(s) required in many circumstances remain poorly defined, to the extent that some authorities have (incredibly) suggested that clear recommendations should not be given. ${ }^{18}$ That approach is fraught with imprecision, so we make the following clear contentions and assumptions:

1. Caprylic acid fractionated ASVs have been widely reported. These are characterized by faster production times and higher yields of antibodies than is achieved by the older ammonium sulfate methodology. ${ }^{14,19-28}$ The antibody yield is approximately double, which contributes to the economic logic. Caprylic acid purification of antibodies gives a yield of approximately 1000 to 1500 vials of ASV per year per horse. ${ }^{29}$ The range is attributed to the nature of the venom in the inoculation regimen and the titre levels achieved. In the basic version of our model, caprylic acid fractionation yielding 1000 vials of final product per horse per year has been assumed.

2. Whole IgG ASVs are as safe as $F(a b)_{2}$ ASVs in terms of adverse reactions and by definition are simpler to produce as they involve less processing steps such as pepsin digestion. ${ }^{24-26,28}$

3. Venoms should be pooled from a variety of sources as this provides greater regional effectiveness for the final ASV product. For production purposes, multisite injection regimens in the horse provide higher titres and lower incidences of local reactions. ${ }^{18,30}$

4. The ASV used in this model is based on one previously suggested for West Africa and is thus effective against the carpet viper (Echis ocellatus), blacknecked spitting cobra (Naja nigricollis), and puff adder (Bitis arietans). ${ }^{14}$ It should be noted that these species are not the only medically significant species in the area, but this combination provides a base example for the model.

5. Antisnake venoms are largely required in the developing world, where "cold chains" for guaranteed refrigeration of liquid ASV are not available or are frequently interrupted. Our model unit is thus geared to produce a lyophilized ASV to enable longer shelf life and higher tolerance to hot climates.

6. An initial production volume of 100000 vials per annum has been assumed for base costing of the financial return on the ASV production unit described in our model. In Asia, a small number of ASV suppliers ( 2 in India and 1 in China), currently produce in excess of this volume, but most manufacturers produce 50000 vials per annum or less.

7. No allowance in this model has been made for additional specific viral protection measures other than those inherent in the production model outlined and the caprylic acid fractionation method (rigorous animal health monitoring, enclosed processing, clean rooms, low pH, 0.22 micron filtration, etc). Despite such additional measures being recommended by some authors, no evidence has been forthcoming that this is a real concern. ${ }^{1,18,39}$ Specific additional measures to provide viral protection filtration are expensive and can add $\$ 1$ to $\$ 2$ cost per vial for countries with greatly constrained health care budgets.

\section{Financial statements to measure return}

In any business, shareholders invest cash to purchase assets, which are used to generate revenue and profit. These assets are recorded on a financial statement known as a balance sheet and are intended to generate a return in terms of profit and/or dividend, which is recorded on a separate financial statement, known as the profit and loss statement.

\section{The assets of production and the balance sheet}

The 3 major asset classes that concern ASV production are land, buildings, and equipment. In the discussion that follows, all costs are in United States (US) dollars. 
Table 2. Horse stabling and veterinary construction requirements and associated costs

\begin{tabular}{|c|c|c|c|c|}
\hline Item & $\begin{array}{l}\text { Area } \\
\text { (square } \\
\text { feet) }\end{array}$ & $\begin{array}{l}\text { Cost/ } \\
\text { square } \\
\text { foot }(\$)\end{array}$ & $\begin{array}{c}\text { Total cost } \\
(\$)\end{array}$ & Details \\
\hline $\begin{array}{l}2 \text { paddock areas, each providing } 80-100 \\
\text { square feet of housing per horse; each ac- } \\
\text { commodating no more than } 50 \text { horses }\end{array}$ & 8640 & 14 & 120960 & $\begin{array}{l}\text { Concrete floored with good drainage; roofed } \\
\text { to } 12 \text { feet high to provide shade and rain } \\
\text { protection; fan-cooled; with feeding stalls }\end{array}$ \\
\hline Blood collection unit & 1000 & 25 & 25000 & $\begin{array}{l}\text { Fully tiled for easy cleaning; with } 4 \text { bleeding } \\
\text { stalls }\end{array}$ \\
\hline Office/work areas & 1000 & 57.5 & 57500 & $\begin{array}{l}\text { Includes fully tiled sterile area for prepara- } \\
\text { tion of injections and storage of plasma; } \\
\text { half tiled dispensary; operating theatre; } \\
\text { necropsy room }\end{array}$ \\
\hline Weighbridge, quarantine area & 5700 & 8 & 45600 & \\
\hline 2 colic boxes, farrier shed & 4500 & 8 & 36000 & \\
\hline Feed storage and distribution & 4800 & 8 & 38400 & $\begin{array}{l}\text { Self contained, secure, vermin-proof, dry hay } \\
\text { store; feed grinder/mixing unit and con- } \\
\text { veyor; concentrated feed store and pro- } \\
\text { cessing unit }\end{array}$ \\
\hline Total & 25640 & & 323460 & \\
\hline
\end{tabular}

\section{Land and horses}

Land requirement for the project is based primarily on the number of horses needed for production. With a target of 100000 vials per year and an assumption of 1000 vials per horse per year, the requirement is 100 horses. Land is required for grazing but also for exercise and maintenance of general health. ${ }^{31}$ The better the condition of the horses, the higher the antibody titre. Western methods advocate 1 to 2 grazing acres per animal. ${ }^{32}$ However, in the developing world, year round grazing is less available and needs to be supplemented by nutritional feeds. The costs for these are dealt with elsewhere in this article (see "Horse Fodder" later).

Assuming the availability of high nutritional feed, an allowance of 0.5 acres per horse (includes both open and covered paddock areas) has been assumed, generating a land allotment of 50 acres. Some Indian manufacturers currently use a lower land allotment per horse, but this is counterproductive as titres may be placed at risk and increasing attention to the humane treatment of the horses is becoming evident. Estimates from India and Pakistan indicate that agricultural land cost is approximately $\$ 31000$ per acre. Land costs are not amortized/depreciated in our model under the assumption that land maintains or increases its value.

The model includes 100 horses for inoculation. The horses should be ages 5 to 8 years and in good health. Purchase cost of $\$ 625$ per horse yields a total asset value of $\$ 62500$. Horses are assumed to have a useful ASV production life of 5 years and are thus amortized/depreciated over a 5-year period.

\section{Buildings}

The building areas are divided into 3 main groups for the purpose of allocating space and calculating construction costs:

1. Horse stabling, including veterinary care, associated facilities, and blood collection unit.

2. Production space, associated offices, plant rooms, and storage.

3. Laboratory, testing, and small-animal house.

\section{Horse stabling and veterinary facilities (Table 2)}

Provision is made for 2 covered paddock areas totaling 4320 square feet each, to provide 80 to 100 square feet of housing per horse (each paddock accommodating no more than 50 horses). Each area is concrete floored with good drainage and roofed to provide shade and rain protection. The paddocks are fan-cooled, contain feeding stalls, and are located with easy access to the open paddock areas and veterinary block. Building cost $=\$ 14$ per square foot; total $=\$ 120960$.

The veterinary block includes a separate 1000 square feet blood collection unit with 4 bleeding stalls, all fully 
tiled for easy and thorough cleaning. Building costs = $\$ 25$ per square foot (total $=\$ 25000$ ).

Adjoining office areas include a fully tiled, sterile area for preparation of injections and storage of plasma, plus a half-tiled dispensary, operating theatre, and necropsy room. Total size $=1000$ square feet built at $\$ 57.5$ per square foot; total $=\$ 57500$.

This area should also include a weighbridge, quarantine area (3700 square feet), 2 colic boxes, farrier shed, together with a self contained, secure, vermin-proof, dry hay store (4500 square feet) and concentrated feed store and processing unit (4800 square feet) to accommodate the feed grinder/mixing unit and conveyor-total area comprising 15000 square feet at $\$ 8$ per square foot. Total space requirement for the veterinary block is 17000 square feet.

Equipment for veterinary use, in addition to standard surgical and laboratory equipment, includes 3 refrigerators (double door, $300 \mathrm{~L}$ capacity each) for venom, plasma, and drugs; an automatic cell counter; bags/bottles for blood collection plus weighbridge; feed grinder/ mixing unit; conveyor (capacity $=750 \mathrm{~kg}$ feed per hour); tractor with trailer; 8 restraints for bleeding stalls (4); operating theatre (1); quarantine area (2); farrier shed (1); hoist for autopsy room plus ceiling fans for cooling all areas and 4 horizontal laminar flow units; 3 air curtains; and 3 negative pressure pumps for maintenance of sterile/clean areas. The cost also covers a computer and software for maintenance of horse immunization and bleeding schedules. Total equipment costs for this category $=\$ 145000$.

\section{Production facility and offices (Table 3)}

A manufacturing facility building of approximately 20000 square feet is assumed, including administrative offices. Basic construction costs, including all earthworks, construction, construction materials, provision, and installation of basic utilities and fittings, are estimated at \$25 per square foot. This figure does not include specialized finishing and services for cold rooms and sterile areas (total of 6000 square foot) for which an additional $\$ 25$ per square foot of construction cost is assumed.

Space allocation is as follows: production processing room (1000 square feet); sterile cold rooms for separation and storage of plasma (500 square feet); ancillary plant rooms (6000 square feet); washing and sterilization (1000 square feet); filling and sealing room (2500 square feet); labeling and packing room (500 square feet); storage rooms for packaging and chemicals (2000 square feet); finished product storage (1000 square feet of cold room); and offices, reception, goods in/out, washrooms, and circulation space (5500 square feet).

The production processing area is a designated sterile area to Class $\mathrm{C}$ level as is the plasma storage room and washing/sterilization areas. The filling and sealing room is a Class A environment. Classes of clean room denote the number of particles of greater than 0.5 micron per cubic meter of air. Class A is necessary to provide greater quality and protection against potential contamination.

Building costs are amortized/depreciated over 25 years.

Table 3. Production unit specifications and costs for construction

\begin{tabular}{|c|c|c|c|c|}
\hline & $\begin{array}{l}\text { Area } \\
\text { (square } \\
\text { feet) }\end{array}$ & $\begin{array}{l}\text { Cost/ } \\
\text { square } \\
\text { foot }(\$)\end{array}$ & $\begin{array}{l}\text { Total cost } \\
\quad(\$)\end{array}$ & Description \\
\hline Production processing & 1000 & 25 & 25000 & Sterile area to Class C level \\
\hline Sterile cold rooms for separation and storage of plasma & 500 & 25 & 12500 & Sterile area to Class A level \\
\hline Ancillary plant rooms & 6000 & 25 & 150000 & \\
\hline Washing and sterilization & 1000 & 25 & 25000 & Sterile area to Class A level \\
\hline Filling and sealing & 2500 & 25 & 62500 & Sterile area to Class A level \\
\hline Labeling and packing & 500 & 25 & 12500 & \\
\hline Storage packaging and chemical storage & 2000 & 25 & 50000 & \\
\hline Final product storage & 1000 & 25 & 25000 & Cold room \\
\hline $\begin{array}{l}\text { Offices/washrooms reception, goods in/out, washrooms and } \\
\text { circulation space }\end{array}$ & 5500 & 25 & 137000 & \\
\hline $\begin{array}{l}\text { Additional construction costs for specialized finishing and } \\
\text { services for cold rooms and sterile areas that is, } 6000 \\
\text { square feet }\end{array}$ & & 25 & 150000 & \\
\hline Total & 20000 & & 650000 & \\
\hline
\end{tabular}




\section{Plant equipment costs (Table 4)}

Bore well construction costs, including a submersible electric motor to supply a $100000 \mathrm{~L}$ overhead water tank, are assumed at $\$ 25000$ (water consumption is estimated at $70000 \mathrm{~L}$ per day). Estimated costs for provision and installation of a demineralized water purification plant, piping, fittings, distillation column, and stainless steel tank for storage of distilled water are $\$ 150000$. A pure steam generator with a capacity of 200 to $250 \mathrm{~kg}$ per hour is costed at $\$ 25000$, together with a steam sterilizer (chamber volume of $3500 \mathrm{~L}$ ) with trolleys and carriage $(\$ 60000)$ plus 2 autoclaves $(\$ 75000)$, provided to meet cleansing needs of production/laboratory and veterinary plant and equipment.

Electrical power consumption is estimated at 325 $\mathrm{kWh}$. Purchase, installation, and commissioning costs for a $315 \mathrm{kVa}$ transformer are estimated at $\$ 175000$.

A compressor and refrigeration plant room is costed at a total of $\$ 167500$. Allowances for water pumps, pipes, valves and fittings, instrumentation, and fire prevention equipment are $\$ 45000$. A further allowance for furniture and office equipment, including computers, is estimated at $\$ 87500$.

Total plant and equipment costs for the main production and office block are estimated at $\$ 810000$ and are amortized/depreciated over 10 years.

\section{Laboratory and testing area (Table 5)}

Laboratory and testing facilities are estimated as requiring 2000 square feet at $\$ 37.5$ per square foot of Class C facility (\$75 000 total). A small-animal house of 2000 square feet at $\$ 25$ per square foot ( $\$ 50000$ total) is necessary for the production of 2000 mice per month, and provision of $\$ 15000$ is also made for cages and breeding racks.

Laboratory equipment costs are estimated at $\$ 250000$.

\section{Production equipment}

In terms of production equipment, the priorities are sterility, effectiveness of operation, technical capability to control the process, and ease of use, cleaning, and maintenance. The simplest way to ensure these objectives is to source the equipment from a single supplier wherever possible. In this array, all the equipment for production is sourced from Millipore Corporation, Billerica, MA. Millipore has considerable experience in supplying elements of the production process and has the capability to supply the entire array. The use of single source quality equipment negates the reliance on improvised equipment arrays used in developing countries, which can compromise product quality. ${ }^{31}$

Table 4. Production plant profile and equipment costs

\begin{tabular}{|c|c|c|}
\hline Item & Total cost $(\$)$ & Details \\
\hline Bore well construction & 25000 & $\begin{array}{l}\text { Submersible electric motor to supply } 100000 \mathrm{~L} \text { overhead water tank. Water } \\
\text { consumption is estimated at } 70000 \mathrm{~L} \text { per day }\end{array}$ \\
\hline $\begin{array}{l}\text { Demineralized water purifica- } \\
\text { tion plant }\end{array}$ & 150000 & $\begin{array}{l}\text { Piping, fittings, distillation column, and stainless steel tank for storage of dis- } \\
\text { tilled water }\end{array}$ \\
\hline $\begin{array}{l}\text { Pure steam generator and ster- } \\
\text { ilizer }\end{array}$ & 85000 & Capacity of 200 to $250 \mathrm{~kg}$ per hour \\
\hline 2 autoclaves & 75000 & $\begin{array}{l}\text { Meet cleansing needs of production/laboratory and veterinary plant and equip- } \\
\text { ment }\end{array}$ \\
\hline Electrical power & 175000 & $\begin{array}{l}\text { Consumption is estimated at } 325 \mathrm{kWh} \text {; purchase, installation, and commission- } \\
\text { ing costs for } 315 \mathrm{kVa} \text { transformer, high tariff and low tariff switchgear and } \\
\text { distribution boards, including backup generator and switching }\end{array}$ \\
\hline Compressor and refrigeration & 167500 & $\begin{array}{l}\text { HVAC air conditioning system units for both comfort air conditioning and air } \\
\text { handling units, compressor }\left(50 \mathrm{~m}^{3} / \mathrm{h}\right) \text { and refrigeration units for all sterile ar- } \\
\text { eas (Class } 1000) \text { based on the Clestra Clean room system (Clestra Stras- } \\
\text { bourg, France), plus piping, valves, and Millipore sterile filtration (Millipore } \\
\text { Corporation, Billerica MA) }\end{array}$ \\
\hline $\begin{array}{l}\text { Water pumps, pipes, valves and } \\
\text { fittings, instrumentation, and } \\
\text { fire prevention equipment }\end{array}$ & 45000 & \\
\hline Furniture and office equipment & 87500 & \\
\hline Total & 810000 & \\
\hline
\end{tabular}


Table 5. Laboratory specifications and costs for construction

\begin{tabular}{|c|c|c|c|c|}
\hline & $\begin{array}{l}\text { Area } \\
\text { (square } \\
\text { feet) }\end{array}$ & $\begin{array}{l}\text { Cost/ } \\
\text { square } \\
\text { foot }(\$)\end{array}$ & $\begin{array}{c}\text { Total cost } \\
\text { (\$) }\end{array}$ & Description \\
\hline Laboratory and testing area & 2000 & 37.5 & 75000 & Sterile area to Class $\mathrm{C}$ level \\
\hline Small-animal house & 2000 & 25 & 50500 & $\begin{array}{l}\text { Sterile area to Class } C \text { level. Designed for the production of } \\
2000 \text { mice per month and provision of } \$ 15000 \text { is made in } \\
\text { the total for cages and breeding racks. }\end{array}$ \\
\hline Total & 4000 & & 125000 & \\
\hline
\end{tabular}

\section{Process}

Once the plasma has been separated, it is placed in a disposable mixing bag (50 L, $100 \mathrm{~L}$, or 200 L capacity) with an integral, magnetically driven impeller and placed in the Mobius MIX200 Mixing System (Millipore Corporation, Billerica MA). This flexibility in processing amount is ideal for a unit that may be producing a variety of ASVs. Bags of plasma can thus be readily stored and changed as required. The mixing bag has access points for caprylic acid administration, and precipitation takes place in the bag under monitoring. The precipitate remains in the bag and is disposed of with the bag after the batch is processed.

Once the precipitation is complete, the supernatant is driven by pump to a Polygard 5 micron filter housing (Millipore Corporation, Billerica MA) and filter and then pumped to a Pelicon Automated ultrafiltration and concentration system (Millipore Corporation, Billerica MA). This system can be provided with additional tanks to contain concentration chemicals and preservatives such as phenol and thimerosal. The concentration process is Supervisory Control and Data Acquisition monitored and automated to avoid error, as is the addition of preservatives. The final mixture is then pumped to sterilization through a Durapore Hydrophilic 0.22-micron filter (Millipore Corporation, Billerica MA), in the Class I sterile area and then goes on to filling and lyophilization. Integrity testing of the filters is performed by Integritest4 automated testing equipment (Millipore Corporation, Billerica MA) to ensure consistent quality of filtration. Total serum production equipment is costed at $\$ 249000$, which may be subject to reduction through commercial negotiations.

\section{Envialation and lyophilization}

The final phase of production involves filling or envialation and lyophilization. The filling of the vials, capping, and sealing is carried out in a Class A clean en- vironment. The equipment should be fully automatic with a digital programmer.

The ability to maintain ASV in an effective form will require lyophilization. The system should have sterilization in place and cleaning in place and reach shelf temperatures of $-55^{\circ} \mathrm{C}$ and condenser temperatures of $-7^{\circ} \mathrm{C}$. Potential suppliers in Asia include Shanghai Tofflon Science and Technology Co Ltd, Shanghai, China, who supply equipment used by a number of manufacturers. Due to the criticality of these 2 elements and the quality of the final product, $\$ 400000$ has been included into the cost estimate. It is worth noting that the importation of lyophilization equipment may be subject to special import authorities because of their potential use in bioweaponry.

\section{Means of production and the profit and loss account (Tables 6-8):}

\section{Labor}

Labor costs are itemized in Table 7 and have been derived from Indian/Pakistan market rates with the exception of the key scientific roles, which have been escalated to ensure top quality staff can be recruited into these areas. Quality and effectiveness requirements determine that high-grade scientific expertise is utilized to monitor production and critical testing of product. Staffing costs and levels for other posts are based on local estimates for horse care, production, and administration.

\section{Venom}

Venom costs are based on the inoculation schedule in the original design paper $^{14}$ and therefore include $5 \mathrm{~g}$ each of Bitis arietans and Echis ocellatus venoms and 6 $\mathrm{g}$ of Naja nigricollis venom plus $2 \mathrm{~g}$ additional of each venom for testing purposes postproduction. 
Table 6. Key production categories used in the production of antisnake venom. All costs are in US dollars

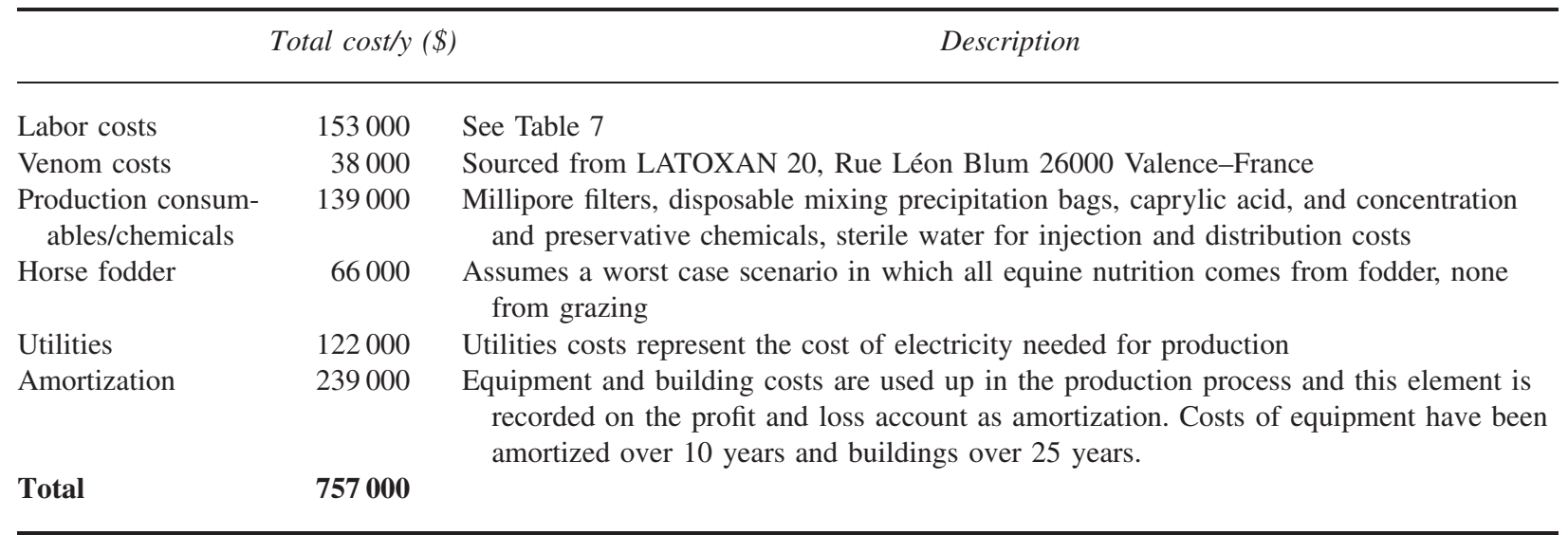

\section{Production consumables}

The Millipore filters and disposable mixing precipitation bags are calculated based on number of batches produced. In this model, 24 batches per annum are assumed, totaling $\$ 49475$.

\section{Production chemicals}

The key production chemical is caprylic acid, which is costed at $\$ 300$ per liter. On a 24-batch cycle of $200 \mathrm{~L}$ of plasma per batch this would imply a requirement of $240 \mathrm{~L}$ of caprylic acid. Caprylic acid concentrations vary between $5 \%$ and $7 \%$, and experimentation during initial testing will establish the most effective concentration to be used. ${ }^{14,34}$ Concentration and preservative chemicals are included in the total.

Table 7. Labor costs for the antisnake venom unit including technical staff

\begin{tabular}{lc}
\hline \multicolumn{1}{c}{ Personnel category } & $\begin{array}{c}\text { Total yearly cost } \\
(\$)\end{array}$ \\
\hline Scientific: 1 biochemist, 1 chemical engi- \\
$\quad$ neer, 1 microbiologist, 1 mechanical en- \\
$\quad$ gineer @ \$12000 per annum \\
Scientific support: 4 technologists @ \\
$\quad$ \$6000 p.a. \\
Management and supervision: 1 \\
Stabling staff and vet: 23 staff \\
Production operations: 13 staff \\
Administration and security: 9 staff \\
Total labor cost
\end{tabular}

\section{Horse fodder}

The feed costs for maintaining the horses have been calculated on a total cost basis and assume that the grazing land provides virtually no nutritional value. This is unlikely but provides for a worst-case scenario. The daily requirement has been calculated per horse at:

1. Forage $=8 \mathrm{~kg} / \mathrm{d}$ per equine.

2. Concentrated mash feed $=2 \mathrm{~kg} / \mathrm{d}$ per equine.

Total fodder cost for 100 horses is estimated to be $\$ 65700$ per annum.

\section{Reconstitution water, packaging, and distribution}

As discussed in the "Introduction," sterile water required to reconstitute the lyophilized product into injectable form is purchased from a bulk supplier in ampoule form. A production output of 100000 vials of ASV would require a similar number of vials of sterile water at a total cost of $\$ 4000$. In addition, packaging costs of $\$ 4250$ have been included to cover individual vial boxes, batch boxes, and product inserts. Delivery costs of final product to agent or end user organization are estimated to be $\$ 2000$.

\section{Utilities}

Utility costs represent the cost of electricity needed for production, particularly in high use areas such as lyophilization, processing, and maintaining an air-conditioned sterile environment, particularly in Class A areas.

\section{Amortization of equipment}

Equipment and building costs are used up in the production process, and this element is recorded on the prof- 
Table 8. Financial statements for antisnake venom production unit

\begin{tabular}{llll}
\hline \multicolumn{1}{c}{ Balance sheet (\$ million) } & & \multicolumn{1}{c}{ Profit and loss account (\$ million) } \\
\hline Equipment: serum production and envialation and lyophilization & 0.649 & Labor & 0.153 \\
Equipment facilities & 0.955 & Production consumables & 0.139 \\
Equipment: testing & 0.265 & Venom & 0.038 \\
Buildings: veterinary and stabling & 0.323 & Horse feed & 0.066 \\
Buildings: production & 0.650 & Utilities & 0.122 \\
Buildings: testing & 0.125 & Depreciation & 0.239 \\
Land and horses & 1.595 & Marketing, trial, and testing & 0.230 \\
Total assets & $\mathbf{4 . 5 6 2}$ & Total costs & $\mathbf{0 . 9 8 7}$ \\
& & & \\
\hline
\end{tabular}

it and loss account as amortization/depreciation. Costs of equipment have been amortized over 10 years and buildings over 25 years. A cost for this has been included at $\$ 239462$ per annum.

\section{Clinical testing and marketing}

Necessary aspects of provision of ASV are clinical trials of the product for safety and effectiveness. Costs of $\$ 130000$ are included for this activity. This includes staff cost, regulatory expenses, and purchasing an existing ASV as a trial comparator. Also included in this amount are costs for preclinical testing in line with established testing regimens (eg, effective dose-50\%, and lethality, pyrogenic activity, hemorrhagic activity, and myotoxicity testing). ${ }^{14,35,36}$ Such clinical trial costs are a one-time expense that should not recur in subsequent years and may provide the possibility of further cost savings after the first year of production.

In many developing countries, marketing material in the form of brochures and posters outlining effective and efficient treatment and usage of the product will be required, and costs of $\$ 100000$ have been included for this purpose.

\section{The economics and why ASV production is sustainable!}

Based on the above model of operation, it is now possible to prepare both a profit and loss account and balance sheet and to determine likely levels of return (Table 8). This should be looked at firstly in terms of cost leaving the production unit (ie, base costs), and, secondly, other costs that occur before end user administration of the ASV to the patient. Together these will determine the final market price of the ASV.

\section{The price of production}

Assets required to operate the facility are $\$ 4.56$ million, and to generate an acceptable return of $20 \%$ return on assets, $\$ 0.9$ million is the required level of profit for the given asset base, that is, $\$ 4.6$ million $\times 20 \%=\$ 0.9$ million. ${ }^{37}$ This profit, divided across 100000 vials, equals $\$ 9.0$ per vial.

The total cost of production figure is $\$ 0.987$ million, which equates to $\$ 9.87$ per vial. In order, therefore, to generate $20 \%$ return on assets, the total cost per vial equals cost of production plus profit required: $\$ 9.87+$ $\$ 9.00=\$ 18.87$ per vial.

The price, therefore, leaving the unit is $\$ 18.87$ per vial.

Interestingly, the margin of the product, that is, the amount of profit made as a percentage of revenue (also known as return on sale), is $48 \%$. This would appear to be very high and may encourage buyers to demand a price reduction. However, this would demonstrate a misunderstanding of ASV economics as the figures above represent the minimum amounts necessary to generate an acceptable and, therefore, sustainable return. The level of the asset base determines the level of profit required, and the costs involved are what they are.

It is worth emphasizing here that with an ammonium sulfate precipitation method the cost per vial would double in accordance with the reduction of yield with this technique. ${ }^{29}$

\section{Price to market}

The price leaving the unit will not be the final market price due to a number of factors. Firstly, an additional price increase will be made to cover buyers who only want small amounts. Large buyers will expect a reduction in price because of the volume purchased, and, therefore, a sufficient amount must be added to the production price to enable this reduction to be given without 
adversely impacting overall levels of return. Such cost shifting is a commercial reality. Therefore, an appropriate final price would likely be $\$ 22$ per vial.

If the ASV is being produced for nondomestic consumption, that is, produced outside the country of consumption, then an import tax is likely. These typically range from $10 \%$ to $20 \%$ of the total price, resulting in a total price of approximately $\$ 26$ per vial including tax.

\section{Final distribution}

The most common method of ASV distribution is either directly to government purchasers or via agents or specialist distributors. Selling directly to governments is the most cost effective method of supplying to end users as no additional uplift needs to be made in terms of cost. Achieving this relationship, however, would require a specialist sales force and infrastructure to achieve legal registrations, etc. However, the normal method employed by manufacturers is to use agents for distribution. Such agents or distributors will add an additional cost per vial to achieve a return adequate for their business. They will incur costs of maintaining a distribution chain, which, in the case of a liquid ASV, could be significant because of the requirement for a reliable cold chain. If distributors increase the cost price per vial by $30 \%$ to cover their costs and provide a reasonable profit, the final vial price will be $\$ 34$ per vial.

\section{Costs vs current market prices}

The likely end cost to the final user, that is, the government or private hospital, will be approximately $\$ 26$ to $\$ 34$ per vial, depending on distribution strategy. This compares to the current African market price of $\$ 80$ per vial. Significant reductions in cost are, therefore, possible, while still providing acceptable and thus sustainable returns to investors.

\section{Volume impacts—single market}

A further economy is possible based on volume. The above economics are based on an annual volume of production of 100000 vials. However, the equipment array can easily produce 200000 vials in 48 batches each year. For example, if the African venom mix is improved and extended to cover a greater number of species, 200000 vials are likely to be needed in Africa. ${ }^{1}$ In this case, additional costs and assets need to be added to the equation to establish assets and costs required for the higher production level. The asset costs will consist of a further allocation of land and stabling for the additional 100 horses, which, based on the model, would lead to incremental assets of $\$ 1.8$ million.

The required level of profit to achieve a $20 \%$ return on assets on the incremental assets is $\$ 0.36$ million, now making the total unit profit requirement $\$ 1.28$ million.

Incremental costs of venom, utilities, production consumables, chemicals, and horse feed would need to be added. Some nonvariable costs such as amortization/depreciation on the equipment, trial costs, some administration, and production labor are excluded, as they do not vary with the production process. In addition, the cost for a clinical trial is excluded as a single product is being considered. This would generate an additional cost to the unit of $\$ 0.4$ million to produce the additional 100000 vials.

The economics of the unit are now:

- Existing assets + incremental assets $\times 20 \%=\$ 1.28$ million.

- Existing costs + incremental costs $=\$ 1.39$ million

- Costs per vial $=\$ 1.9$ million $/ 200000$ vials $=\$ 6.9$ per vial.

- Required profit $=\$ 1.28$ million $/ 200000$ vials $=\$ 6.4$ per vial.

- Production price $=\$ 6.9+\$ 6.4=\$ 13.3$ per vial

Based on the previous tax and distribution calculations the price per vial to the end user would be $\$ 21$ compared to $\$ 34$ in the 100000 vials per annum model.

\section{Volume impacts-multiple markets}

A further option to increase output is the production of ASV for a different market. For example, in addition to the original ASV for Africa, a second ASV for the Asian market is produced. In this case costs would need to be added to the equation for a further clinical trial.

The economics of the unit are now:

- Existing assets + incremental assets $\times 20 \%=\$ 1.28$ million.

- Existing costs + incremental costs $=\$ 1.487$ million.

- Costs per vial $=\$ 1.487$ million $/ 200000$ vials $=\$ 7.4$ per vial.

- Required profit $=\$ 1.28$ million $/ 200000$ vials $=\$ 6.4$ per vial.

- Production price $=\$ 7.4+\$ 6.4=\$ 13.8$ per vial

This model would enable a similar end user price to be set as in the previous example, that is, $\$ 22$ per vial.

In some Asian countries such as China, the cost per vial is higher than Africa (\$160); however, in countries such as Pakistan, current selling prices are $\$ 10$ to $\$ 15$ per vial depending on whether the ASV is indigenously produced or imported from India. The reason for this 
cost differential is that Pakistan has a very basic production system that is very old and can thus produce ASV very cheaply.

If the intention is to sell into a current low cost market, then a possible answer is a variable pricing strategy. For example, it might be possible to set a price of $\$ 30$ per vial for 100000 African ASV vials and \$15 per vial for the low cost Asian ASV market to generate the necessary revenue of $\$ 4.4$ million required to cover costs plus profit. Variable pricing would still enable African ASV to be sold at a considerable local reduction over current prices and simultaneously provide a competitive product into the low-cost Asian market. Alternatively a single price for both regions could be set at $\$ 22$ per vial, which would enable significant reductions to be achieved in Africa but not the low-cost Asian market.

\section{Titres and why one does not flog a dead horse!}

The above model demonstrates how ASV can be produced sustainably by generating an acceptable return but also a lower price in Africa and higher-cost areas of Asia and Oceania. A further economic variable is the level of titre raised in the horse. The current model assumes that 1000 vials are produced per horse in a year, giving a total of 100000 vials from 100 horses. If multiple injection sites on the upper portion of the neck, close to lymph nodes, are used to inoculate a healthy horse it may be possible to generate an additional 500 vials per horse in the same period. This is a key reason why horses must be kept healthy, exercised, and well fed. ${ }^{31}$ The incremental costs involved in such production are minor and include additional utility costs for processing and additional preservatives and vials. The reduction in price for end users can be significant. For every 100 vials produced per horse in a year, the cost of a vial to the end user declines by $\$ 1$ to $\$ 2$ per vial. If 500 additional vials are achieved per horse, the final price in the initial 100000 vial output model may decline from $\$ 34$ to $\$ 25$. In the case of the higher volume option of 200000 vials for Africa, 500 additional vials per horse would enable a price reduction to $\$ 16$ per vial! Such a reduction is significant in developing countries with limited health budgets.

\section{Conclusions}

The provision of ASV in areas of shortage, which are many, is often characterized by experts, citing a priori assumptions, as being unsustainable. They conclude that the only solution to this problem is to rely on charity from private donors or organizations, ${ }^{1,38}$ although there is little evidence of success with such an approach. The assumption that ASV production and distribution can only be sustained by charitable donation is not, to our knowledge, based on any rigorous analysis of the financial aspects of production or economic sustainability. Given the magnitude of the clinical problem, it is surprising that no individual or organization has to date reported an economic analysis about whether profitability can be achieved.

We are very confident that, by applying our model, many developing nations or nongovernmental agencies will be able to prevail upon new or existing pharmaceutical companies to produce ASV. The potentially perverse and conflicting incentives involving long-established methods and relationships must be recognized and addressed. On close analysis, however, the facts elucidated here for the first time should speak for themselves. Currently, established ASV producers with an interest in avoiding specific recommendations that mandate a change in long established processes with which they are familiar and academics with no experience of financial sustainability, dominate the meetings where these issues are debated. ${ }^{1,18,35}$ We strongly urge them and others to adopt the best methods for sustainability and economic return. We do not presume that our model is perfect, but we are proposing to correct a situation that has gone on much too long without quantitative analysis.

Much additional work remains to be done; for example:

1. It is critically important that clear and specific recommendations be made regarding needed ASV profiles in terms of species and geographic regions to be covered.

2. Advice must be given to government and regulatory bodies that alternatives to the pepsin digested, $\mathrm{F}(\mathrm{ab})_{2}$, ammonium sulfate precipitated ASVs are safe, cost effective, and preferable in developing countries due to sustainability and affordability. Pharmacopoeias must be changed where needed to enable the most efficient processes to be implemented.

3. Equipment manufacturers must be engaged to seek innovative solutions to produce ASV, which simplify the process, maintain quality, and provide technical, maintenance, and training support.

4. The positives of ASV production should be stressed rather than continually focusing on unestablished negatives, which deter good providers from entering the market and thereby lead to the assumption that "handouts" are the only way to fund ASV sustainably.

We believe that we have demonstrated that ASV can be produced at affordable prices and sustainably if the problem is approached in the correct manner-which 
will also optimize the issues of effectiveness, purity, supply and demand, economic considerations, and safety. If we are to avoid Taleb's observation that "we spend our time in small talk, focusing on the known and the repeated," we have to aggressively reconsider what has historically, and erroneously, been considered the improbable "black swan" of sustainable, affordable $\mathrm{ASV}^{40}$ The solution is not more general commentary on issues and solutions that are purely applicable in a western context - the historical approach of the World Health Organization Department of Medicines, Policy and Standards, ${ }^{1,18,35}$ and it is hoped that the exercise described here will lead to a more pragmatic and problem-solving approach, particularly as better approaches to solving the ASV availability crisis are now available. ${ }^{41}$

\section{References}

1. World Health Organization. Rabies and Envenomings: A Neglected Public Health Issue. Geneva, Switzerland: World Health Organization; 2007.

2. Warrell DA. Tropical health: venomous bites and stings in the tropical world. Med J Aust. 1993;159:773-779.

3. Warrell DA. Clinical toxicology of snakebite in Asia/Africa and the Middle East/Arabian Peninsula. In: White J, Meier J, eds. Handbook of Clinical Toxicology of Animal Venoms and Poisons. Raton, FL: CRC Press; 1995.

4. Laing GD, Renjifo JM, Ruiz F, et al. A new pan African polyspecific antivenom developed in response to the antivenom crisis in Africa. Toxicon. 2003;42:35-41.

5. Muguti G, Maramba A, Washaya CT. Snake bites in Zimbabwe: a clinical study with emphasis on the need for antivenom. Cent Afr J Med. 1994;40(4):83-88.

6. Wilde H, Thipkong P, Sitprija, V, Chaiyabutr N. Hetrologous antisera and antivenins are essential biologicals: perspectives on a worldwide crisis. Ann Intern Med. 1996; 125:233-236.

7. Warrell DA. WHO/SEARO guidelines for the clinical management of snakebite in the Southeast Asian Region. SE Asian J Trop Med Pub Hlth. 1999;1:1-85.

8. Cheng AC, Winkel KD. Snakebite and antivenoms in Asia-Pacific: wokabaut wantaim raka hebou ("Walking Together"). Med J Aust. 2001;175:648-651.

9. Cheng AC, Currie BJ. Venomous snakebites worldwide with a focus on the Australia-Pacific region: current management and controversies. J Intensive Care Med. 2004; 19:259-269.

10. Dart RC, Stark Y, Fulton B, Koziol-McLain J, Lowenstein SR. Insufficient stocking of poisoning antidotes in hospital pharmacies. JAMA. 1996;276:1508-1510.

11. White J, Warrell DA, Eddleston M, Currie BJ, Whyte IM, Isbister GK. Clinical toxinology-where are we now? $J$ Tox Clin Tox. 2003;41(3):263-276.

12. Chippaux JP. Snake Venoms and Envenomations. Malabar, FL: Krieger Publishing Company; 2006:211-246.

13. Gutiérrez JM, Higashi HG, Wen FH, Burnouf T. Strength- ening antivenom production in Central and South American public laboratories: report of a workshop. Toxicon. 2006;49:30-35.

14. Gutiérrez JM, Rojas E, Quesada L, et al. Pan-African polyspecific antivenom produced by caprylic acid purification of horse IgG: an alternative to the antivenom crisis in Africa. Trans Roy Soc Trop Med Hyg. 2005;99:468-475.

15. Stock RP, Massougbodji A, Alagon A, Chippaux JP. Bringing antivenoms to Sub-Saharan Africa. Nature. 2007;25:173-177.

16. Theakston RD, Warrell DA. Crisis in snake antivenom supply for Africa. Lancet. 2000;356:2104.

17. Simpson ID. Time for an alternative perspective: the eternal problem of supply and quality of anti snake venom in the developing world-'it's the economy stupid.' Wilderness Environ Med. 2008;19:186-194.

18. Theakston RDG, Warrell DA, Griffiths E. Report of a WHO workshop on the standardization and control of antivenoms. Toxicon. 2003;41:541-557.

19. Chanutin A, Curnish, RR. The precipitation of plasma proteins by short-chain fatty acids. Arch Biochem Biophys. 1960;89:218-220.

20. Steinbuch M, Audran R. The isolation of IgG from mammalian sera with the aid of caprylic acid. Arch Biochem Biophys. 1969;134:279-284.

21. McKinney MM, Parkinson A. A simple, non-chromatographic procedure to purify immunoglobulins from serum and ascites fluid. J Immunol Meth. 1987;96:271-278.

22. Dos Santos MC, D'Imperio-lima MR, Furtado GC, Colletto GMDD, Kipnis ZL, Dias Da Silva W. Purification of F(ab')2 anti-snake venom by caprylic acid: a fast method for obtaining IgG fragments with large neutralization activity, purity and yield. Toxicon. 1989;27:297-303.

23. Perosa F, Carbone R, Ferrone S, Dammacco F. Purification of human immunoglobulins by sequential precipitation with caprylic acid and ammonium sulfate. J Immunol Meth. 1990;128:9-16.

24. Saetang T, Treamwattana N, Suttijitpaisal P, Ratanabanangkoon K. Quantitative comparison on the refinement of horse antivenom by salt fractionation and ion-exchange chromatography. J Chromatogr B Biomed Sci Appl. 1997; 700:233-239.

25. Otero-Patiño R, Cardoso JL, Higashi HG, et al. A randomized, blinded, comparative trial of one pepsin-digested and two whole IgG antivenoms for Bothrops snake bites in Uraba, Colombia. Am J Trop Med Hyg. 1998;58:183-189.

26. Otero R, Gutiérrez JM, Rojas G, et al. A randomized blinded clinical trial of two antivenoms, prepared by caprylic acid or ammonium sulphate fractionation of $\mathrm{IgG}$, in Bothrops and Porthidium snake bites in Colombia: correlation between safety and biochemical characteristics of antivenoms. Toxicon. 1999;37:895-908.

27. Raweerith R, Ratanabanangkoon K. Fractionation of equine antivenom using caprylic acid precipitation in combination with cationic ion-exchange chromatography. J Immunol Meth. 2003;282:63-72.

28. Otero R, León G, Gutiérrez JM, et al. Efficacy and safety 
of two whole IgG polyvalent antivenoms, refined by caprylic acid fractionation with or without beta-propiolactone, in the treatment of Bothrops asper bites in Colombia. Trans Roy Soc Trop Med Hyg. 2006;100:1173-1182.

29. Morais V, Massaldi H. Economic evaluation of snake antivenom production in the public system. J Venom Anim Toxins incl Trop Dis. 2006;12:497-511.

30. Chotwiwatthanakun C, Pratanaphon R, Akesowan S, Sriprapat S, Ratanabanangkoon K. Production of potent polyvalent antivenom against three elapid venoms using a low dose, low volume, multi-site immunization protocol. Toxicon. 2001;39:1487-1494.

31. Fiennes RN. Ecological concepts of stress in relation to medical conditions in captive wild animals. Proc Royal Soc Med. 1968;61:161-162.

32. British Horse Society. Available at http://www.bhs.org. uk/_Attachments/resources/818_S4.pdf. Accessed August 11, 2008.

33. Government of Sindh. Anti Snake Venom Laboratory: (Pre Feasibility Report). Karachi: Health Department, Government of Sindh; 2005.

34. Rojas G, Jiménez JM, Gutiérrez JM. Caprylic acid fractionation of hyperimmune horse plasma: description of a simple procedure for antivenom production. Toxicon. 1994;2:351-363.

35. World Health Organisation. Progress in the characterization of venoms and standardization of antivenoms WHO Offset Publ. 1981;58:1-44.

36. Theakston RGD, Reid HA. Development of simple standard assay procedures for the characterization of snake venoms. Bull World Health Organ. 1983;61:949-956.

37. Menou V, White A, Savitz A, Mehrpouya A. Global pharmaceutical sector report. Available at http://www.ecology express.com/guide/document/innovest_industrysample.pdf. Accessed January 14, 2008.

38. Gutierrez JM, Theakston RDG, Warrell DA. Confronting the neglected problem of snakebite envenoming: the need for a global partnership. PLoS Med. 2006;(6):e150.DOI: 10:1371/journal.pmed.0030150

39. Burnouf T, Griffiths E, Padilla A, Seddik S, Stephano MA, Gutiérrez JM. Assessment of the viral safety of antivenoms fractionated from equine plasma. Biologicals. 2004; 32:115-128.

40. Taleb NN, The Black Swan: The Impact of the Highly Improbable. New York, NY: Random House; 2007.

41. Simpson ID, Norris RL. The global snakebite crisis-a public health issue misunderstood, not neglected. Wilderness Environ Med. 2009;20:43-56. 